\title{
CLARIFYING THE MEANING OF MATHEMATICAL OBJECTS AS A PRIORITY AREA OF RESEARCH IN MATHEMATICS EDUCATION ${ }^{1}$
}

\author{
Juan D. Godino and Carmen Batanero \\ Universidad de Granada
}

\begin{abstract}
The main thesis of this chapter is that the epistemological and psychological analyses concerning the nature of mathematical objects play a fundamental role in addressing certain research questions in mathematics education. In particular - the question of assessment of students' knowledge, and that of the selection of didactical situations. The thesis is justified within the framework of a pragmatic and relativist theory of meaning of mathematical objects, outlined in the chapter. The framework emphasizes the complex and systemic nature of the meaning of mathematical objects and stresses the institutional and cultural contexts of the teaching and learning processes in mathematics.
\end{abstract}

Key words: epistemology, nature of mathematics, didactic of mathematics, institutional and personal knowledge, semiometry, ecology of meanings.

\section{The Nature Of Mathematical Objects: The Question Of Meaning}

The specific aim of Mathematics Education is to study the factors that affect the teaching and learning of mathematics and to develop programs to improve the teaching of mathematics. In order to accomplish this aim Mathematics Education must consider the contributions of several disciplines: Psychology, Pedagogy, Sociology, Philosophy, etc. However, the use of these contributions in Mathematics Education must take into account and be based upon an analysis of the nature of mathematics and mathematical concepts, and their personal and cultural development. Such epistemological analysis is essential in Mathematics Education, for it would be very difficult to suitably study the teaching and learning processes of undefined and vague objects.

Thus, research in Mathematics Education cannot ignore philosophical questions such as:

- What is the nature of mathematical objects?

- What roles are played by human activity and sociocultural processes in the development of mathematical ideas?

- Is mathematics discovered or invented?

- Do formal definitions and statements cover the full meaning of concepts and propositions?

\footnotetext{
${ }^{1}$ A. Sierpinska y J. Kilpatrick (Eds.), Mathematics Education as a research domain: A search for identity (pp. 177-195). Dordrecht: Kluwer, A. P.
} 
- What is the role played, in the meaning of mathematical objects, by their relationships with other objects, the problems in which they are used and the different symbolic representations?

It must also recognize the complexity of these questions and the variety of possible answers. As A. Dou says in the preface to Cañón's book (1993), 'The ontology of mathematical entities and, even more so, its epistemology is interpreted in an incredibly disparate way and it still remains a mystery (p.14)'. Piaget (1979) also stated, 'it was never possible to agree upon what in fact mathematical entities are (p. 147)'. The acknowledgment of the difficulty of the questions does not mean, however, that attempts at their clarification should be given up. We think it is important to address them if some progress is to be made in the setting of a coherent research program aiming at defining the field of Research in Mathematics Education.

The essential role of the study of the meaning of mathematical objects for mathematics education is emphasized, amongst others, by Balacheff (1990), who stated: 'A problem belongs to a problématique of research of mathematics teaching if it is specifically related to the mathematical meaning of pupils' behavior in the mathematics classroom (p. 258)'. Sierpinska (1994) stresses the close relationship between the notions of meaning and understanding.

However, within this area of knowledge there is a lack of explicit theories regarding the meaning and genesis of mathematical concepts and procedures according to the new tendencies in the Philosophy of Mathematics (Wittgenstein 1953; Lakatos 1976; Kitcher 1984; Tymoczko 1986; Ernest 1991; Dossey 1992).

In this paper we present a theory of the nature and meaning of mathematical objects (concepts, propositions, ...), which takes into account their epistemological and psychological dimensions. This theoretical framework is applied to frame certain basic research questions in Mathematics Education.

The theory of the meaning of mathematical objects that we present has an intrinsic kinship with Chevallard's anthropological approach to mathematical knowledge (especially his ideas of objet and rapport à l'objet $(1991 ; 1992)$ and Wittgenstein's doctrine of 'meaning as use' (1953) as interpreted by Kutschera (1971), McGinn (1984) and McDonough (1989). Our educational perspective and integrative intention lead us to complement these approaches with theoretical elements such as personal or mental objects, in line with a psychological epistemology (Kitcher 1984) and the psychological theory of situated cognition (Brown, Collins and Duguid 1989).

We highlight the view of mathematical objects as signs of cultural units, whose systemic and complex nature cannot be described merely by formal definitions when the perspective taken is that of the study of teaching and learning processes. Based on this viewpoint, we intend to explain some learning misconceptions and difficulties, not only in terms of mechanistic mental processes, but by recognizing the complexity of meaning and the necessarily incomplete teaching processes in schools.

Finally, we shall study the possible effectiveness of the presented theoretical system in formulating a 'problématique' of research into Mathematics Education in which the centre of interest in studying meaning and understanding is shifted from the mental processes to the institutional and cultural contexts. This change of perspective has been proposed in philosophy of language by Wittgenstein, in psychology - by authors following the cultural psychological trend which also emphasizes the idea of 
meaning (Bruner 1990), and, within Mathematics Education, by ethnomathematical studies (e.g. Bishop 1988; Nunes 1992; D'Ambrosio 1994)

\section{Institutional And Personal Meaning Of Mathematical Objects: A Pragmatic And Relativist Theory}

According to the aforementioned tendencies in the Philosophy of Mathematics, the epistemological and cognitive assumptions that serve as a basis for our theory are the following:

a) Mathematics can be seen as a human activity involving the solution of socially shared problem-situations, which refer to the real or social world or which are within the realm of mathematics itself. As a response or solution to these external and internal problems, mathematical objects (concepts, procedures, theories, etc.) progressively emerge and evolve. People's acts must be considered, therefore, as the genetic source of mathematical conceptualization, in line with the Piagetian constructivist theories.

b) Mathematical activity creates a symbolic language in which problem situations and their solutions are expressed. The systems of symbols, as culturally embodied, have a communicative function and an instrumental role, which changes the person him or herself when using the symbols as mediators (Vygotskii 1934; Rotman 1988).

c) Mathematical activity aims, among others, at the construction of logically organized conceptual systems. The logical organization of concepts, theorems, and properties also explains the great number of problems involved in the learning of mathematics: A system cannot be simplified into a sum of isolated components because what makes it a system are exactly the interrelationships between the components.

It is thus necessary to distinguish two interdependent dimensions in the genesis of the mathematical knowledge: the personal (subjective or mental) dimension and the institutional (objective, contextual) dimension. Given that subjects grow up and live within different institutions, their knowledge is mediated by the peculiarity of the corresponding contextual knowledge. It is important to recognize that mathematics, as a cultural reality (Wilder 1981), adopts different 'ways of life and of operation' within different human groups. Nevertheless, we should recognize the dominant and controlling role of the formal and logical deductive organization adopted by mathematics in the institution of the 'producer of knowledge', mainly due to its effectiveness in setting and solving new problems and in communicating the solutions.

Hence, we recommend considering the objects and their meaning in a relativist way, regarding different institutions (in the sense that will be described later in the chapter).This will allow us to better appreciate the adaptation (or transposition, as Chevallard says) and mutual influences that mathematical objects undergo as they are transmitted between people and institutions.

Below, we shall define the theoretical concepts of practice, objects (personal and institutional) and meaning, by adopting as a primitive the notion of problem-situation, attempting to make evident and operative the aforementioned triple nature of mathematics, the personal and institutional genesis of mathematical knowledge and the mutual interdependence between the latter two. The presentation of the theoretical notions using a definition format does not intend to establish any 'axiomatics' for the complex ontological and epistemological issues that are raised. The definition format has been used in the aim of expressing our thoughts in a precise way and to facilitating 
the analysis and debate thereof. The concept of statistical association will be used to illustrate the proposed theoretical model and make it less abstract and generic. A more detailed presentation of the framework can be found in Godino and Batanero (1994), where the concept of mean is used as another example. In this chapter, the implications of the theoretical framework are extended and systemized from the point of view of developing a research agenda for Mathematics Education.

\section{Mathematical Problems, Practices and Institutions}

Our theoretical system is based on the notion of problem-situation. We think that this notion takes into account the main components of the activity of mathematising as described by Freudenthal (1991), and three types of situations proposed by Brousseau (1986) (action, formulation/ communication and validation).

We shall assume that, for any given person, a problem-situation is any type of circumstance in which mathematising activities are needed.

As examples of mathematising activities we could highlight:

- building or looking for possible solutions that are not immediately accessible;

- inventing an adequate symbolization to represent the situations and the solutions found and to communicate these solutions to other people;

- producing new meaningful expressions and statements through symbolic manipulations;

- justifying (validating or arguing) the proposed solutions;

- generalizing the solution to other contexts, problem-situations and procedures.

These activities are not exclusive to mathematics, except when mathematical objects, such as numbers, geometric figures, functions, logical reasonings, etc., take part in them. In our case in which we try to define the notions of object, meaning and understanding in mathematics, we need to consider the notion of mathematical problemsituation - or mathematising - as primitive.

The generality that we attribute to the notion of mathematical problem-situation is motivated by our desire to integrate the invention, justification, application and diffusion contexts in the same epistemological model of mathematical knowledge.

Problem-situations do not appear in isolation, independently from one another, rather they constitute classes of interrelated problem-situations, sharing similar solutions, representations, etc., which we shall call problem fields.

We consider the notions of problem-situation and problem field to be very general,and dependent on the institutional context and the subjects involved. Subjects are not required to accomplish all the different types of mathematising activities, or to completely build a mathematical model. School activities are in fact problem-situations if the students do not have trivial and immediate answers for what they are asked to do.

Let us consider the following item as an example of problem-situation:

Problem 1: In a medical center 250 people have been observed in order to determine whether the habit of smoking has some relationship with bronchial disease. The following results have been obtained: 


\begin{tabular}{|l||l||l||l||}
\hline & Bronchial disease & No bronchial disease & Total \\
\hline \hline Smoker & 90 & 60 & 150 \\
\hline \hline Non-smoker & 60 & 40 & 100 \\
\hline \hline Total & 150 & 100 & 250 \\
\hline
\end{tabular}

Using the information contained in this table, would you think that, for this sample of people, bronchial disease depends on smoking?

This is the simplest form of a contingency table or cross-tabulation, which is used to present the frequencies in a population or sample, classified by two statistical variables. It is a particular item of the problem field from which has originated the notion of statistical association. This concept extends the notion of functional dependence to cases in which the independent variable does not determine a unique value but a frequency distribution for the dependent variable.

We might enunciate other similar situations by changing the context, the intensity of the dependence between the variables, the numerical values of the frequencies, etc. We could also increase the number of rows and columns or consider other types of variables, such as, for example, inquiring into the linear correlation between two quantitative variables.

The data of problem 1 suggest the following problem from a different field:

Problem 2: Assuming that the data of problem 1 have been drawn at random from a given population, what would be your estimate of the proportion of smokers in this population? Could you give an interval for the variation of the proportion of smokers in the population, with an error probability smaller than $5 \%$ ?

This problem and other similar problems, for example, the question of deciding if the estimation given is optimum, in what sense it is optimum, or the problem of computing the sample size necessary to produce a given size confident interval actually belong to a different problem field, the field of estimation of paramenters..

What actions could be carried out by people whithout specific knowledge of statistics to solve this type of problems? In our research (Batanero et al., 1996) we proposed the contingency table problem to a sample of 213 students, without instruction in this subject. Some of them compared the ratio of bronchial disease in the smokers $(90 / 150)$ with the ratio of bronchial disease in non-smokers $(60 / 100)$ and, as these ratios were identical, they argued that there was no relationship between the two variables in the sample given, which is the correct answer (let us denote this 'way of solving' or practice by $\mathrm{P} 1)$. Other students also obtained the correct answer by comparing the proportion of bronchial disease in smokers (90/150) with the proportion of bronchial disease in the total sample (150/250) (P2). Another practice, (P3), was to compare the ratio between the number of people with bronchial disease and the number of people with no bronchial disease in smokers $(90 / 60)$ with the same ratio in nonsmokers $(60 / 40)$. 
The processes of solving problems from this problem field require relating or operating with mathematical objects such as frequencies, ratios, totals, etc. or identifying previously built objects, satisfying some given conditions. Situations and practices of this kind are essential for the building of the concept of statistical association. In general, the basic role of the activity -in its wider sense- for building mathematical objects is synthesized in definitions 1 and 2 .

Using these and the following definitions, we try to build a theoretical model that allow us to distinguish the subjective and institutional dimensions of knowledge, meaning and understanding in mathematics, as well as to point out the relationships between both dimensions. Furthermore, we propose to base our epistemological model for mathematics on the activity of subjects involved in problem-situations, mediated by semiotic instruments provided by institutional contexts.

DEFINITION 1: Let us call practice any action or manifestation (linguistic or otherwise) carried out by somebody to solve mathematical problems, to communicate the solution to other people, so as to validate and generalize that solution to other contexts and problems.

These different types of practices (action, formulation/ communication and validation) attempt to consider the category of situations that generate forms of mathematical knowledge as described by Brousseau (1986).

Concrete and abstract objects intervene in mathematical practices and they can be represented in textual, oral, graphical or even gestural form.

In general, rather than in one particular practice for solving a specific problem, we are interested in types of practices, that is to say, in the operative invariants shown by people during their actions concerning problem-situations. These invariants shall be called prototype practices. Generally, for each field of problems and, in principle, for each person we can identify a system of prototype practices.

The development of mathematical activity, carried out by people involved in problem solving, is not usually a linear and deductive process. On the contrary, it is fraught with failed attempts, trials, errors, and unfruitful procedures that are abandoned. Thus, we consider that it is necessary to introduce the notion of meaningful personal practice:

DEFINITION 2: We say that a practice is meaningful (or that it makes sense) for a person if, for that person, this practice fulfills a function in solving a problem, or in communicating the solution to another person, or in validating and generalizing the solution to other contexts and problems.

Generally, problem-situations and their solutions are socially shared, that is to say, they are linked to institutions. For example, different collectives are interested in studying statistical association problems. The contingency table problem, or some variation thereof, could be of interest to 'secondary school students', 'university students', 'medical researchers', 'public health chiefs', 'applied statisticians', etc. Each of these groups has different aims and uses different tools for solving these problems. Whilst for secondary school students the descriptive study is sufficient, at the University, students must apply the Chi-square test of independence. Practices P1 to P3 would be considered insufficient to solve the problem at the University level. Applied statisticians and researchers would have statistical packages available and would include different other variables in the analysis, to evaluate whether the empirical association could be influenced or not by these other variables. 
These groups of people are examples of institutions in which problem-situations are dealt with using specific aims, tools and practices, and so they constitute differentiated epistemological formations. Therefore, we propose the following descriptions of the notions of institution and system of social practices..

DEFINITION 3: An institution (I) is constituted by the people involved in the same class of problem-situations, whose solution implies the carrying out of certain shared social practices and the common use of particular instruments and tools.

We shall use the name of mathematical institution (M) for people involved in solving new mathematical problems, i.e. for the producers of new mathematical knowledge. Other institutions involved in mathematical problems are applied mathematicians, scientists, technicians, teaching institutions, etc..

As has been shown in the example, specific practices for solving a field of problems are carried out within different institutions. It is essential to consider the set of such practices from a systemic perspective, with the aim of inquiring into its main components and structure. In teaching institutions, this information should be used as a reference universe for selecting representative samples of teaching and assessment situations.

DEFINITION 4: The system of institutional practices of an institution I, linked to a field of problems $C$, is constituted by the meaningful practices to solve $C$, shared within I.

The social nature of these practices implies that they are observable. As examples of social practices, we may quote: problem descriptions, symbolic representations, definitions of objects, statements of propositions and procedures characteristic of the field of problems, argumentations. We shall denote the system of institutional practices by $\mathrm{P}_{\mathrm{I}}(\mathrm{C})$.

\section{Institutional and Personal Objects}

Examples P1 to P3 of students' actions in the solving process of the contingency table problem constitute the phenomenological substratum for students' intuitive conceptualization of statistical association. For example, when a particular student uses practice $\mathrm{P} 2$ it is because he supposes that the relative frequency distribution for the dependent variable must change in the case of dependence when we restrict the sample to a given value of the independent variable (smokers). This practice is, for different people, an operative invariant for this type of problems. Its mathematical formalization is expressed in the following definition for independence: 'Independence between two statistical variables, $A$ and $B$, means the invariance of the distribution of $B$ when conditioned by a value of $A^{\prime}$. The operative invariants linked to P1 and P3 lead to different characterizations for statistical association.

When widening the scope of the contingency table problem, more complete mathematical procedures would be needed. For example, testing hypotheses concerning association requires completing the Chi square test or the Fisher test. The measures of association (PHI, Contingency C and V, Goodman Lambda, etc.) have been created to assign a degree to the intensity of association. Therefore, the concept of association has emerged and evolved progressively over time and practices created to solve problems. It has also generated some related concepts, such as multiple or partial association. Moreover, it has been the basis for developing new problem fields and tools for solving them. For example, the problem of geometrical representation and reduction of dimension in multivariate data was solved using the correlation coefficient and led to factor analysis techniques. 
This process has a general character: Mathematical objects are abstract entities that emerge progressively from the socially shared system of practices, linked to the activities of solving a given field of mathematical problems. According to Morin (1977), the notion of emergence means that the overall product of the activities that form a system has its own qualities, which produce feedback from the activities of the system from which they cannot be separated.

Since practices may vary from one institution to another, we must give the object a relativity with respect to institutions. In our example, the concept of association is very different for applied statisticians and for secondary school students, because the things that the students are able to say about association and to do in association situations are very limited. Thus, we propose the following definition:

DEFINITION 5: An institutional object $O_{I}$ is an emergent of the system of social practices linked to a field of problems, that is to say, an emergent of $P_{I}(C)$. The elements of this system are the empirical indicators of $O_{I}$.

The emergence of the object is progressive over time. At any given time the object is recognized as such by the institution, but even afterwards it undergoes progressive transformations as the field of problems widens. The institutional objects are the constituents of the objective knowledge in the sense described by Ernest (1991).

The progressive nature of the construction of scientific objects has its parallels in the learning by the subject and in the invention of new mathematical ideas. 'Not only in its practical aspects, but also in its theoretical aspects, knowledge emerges from problems to be solved and situations to be mastered. It is true for the history of science and technologies; it is also true for the development of cognitive instruments of young children' (Vergnaud 1982, p. 31).

During the learning process, students may develop some practices that do not coincide with those considered appropriate by the teaching institution.

Practices P1 to P3 are examples of correct practices for solving the contingency table problem, from the point of view of the descriptive study of association (there is no inference from this sample to a wider population). But some of our students used procedures that were statistically incorrect, even from the descriptive point of view, as in the following cases:

- P4: Using only the cell of smokers with bronchial disease (90), to reason that there is dependence between the variables, because this frequency is maximum.

- P5: Basing a judgment only on the frequencies in one row or one column of the table; for example, reasoning that there is dependence between the variables because the number of smokers with bronchial disease (90) exceeds the number of healthy smokers (60).

- P6: Not taking into account the empirical data and basing a judgment on preconceived ideas about the association that ought to exist between the variables.

We introduce the notions of 'a system of personal practices' and 'personal object' to differentiate between objective and subjective dimensions of knowledge.

DEFINITION 6: The system of personal practices linked to a field of problems $C$ is constituted by the prototype practices that a person carried out to solve $C$. This system will be denoted by $P_{p}(C)$. 
DEFINITION 7: A personal object $O_{p}$ is an emergent of the system of personal meaningful practices linked to a field of problems, that is to say, an emergent of $P_{p}(C)$.

The emergence of the object is progressive during the subject's lifetime, as a consequence of the subject's experience and learning. Personal objects are constituent parts of subjective knowledge (Ernest 1991).

\section{Institutional and Personal Meaning of an Object}

Objects are named and described by means of certain practices that are usually considered as the definitions of the objects (these practices are even identified with the object through metonymy). However, Vergnaud (1990) considers that the meaning of a mathematical object, from a didactical and psychological point of view, cannot be reduced merely to its definition. We agree with this author in that the meaning of mathematical objects must refer to the actions ('interiorized' or otherwise) that the subject carries out in relation to these objects. We also think that it is necessary to distinguish between the institutional and the personal dimension of meaning. For example, the term 'association' has different meanings in different people and institutions. In secondary schools the curricula propose solving descriptive problems of contingency tables and linear bivariate correlation and regression. Only simple data sets are studied. The students compare the intensity of association using the correlation coefficient, but they do not compute confidence intervals nor do they test hypotheses concerning this coefficient. At the university level, students would perform the inferential study; they use the square correlation coefficient to decide the percentage of variability explained in the analysis of variance and to decide the order in which different independent variables are to be included in stepwise multiple regression analysis. A statistical consultant would decide how many factors should be retained using the size of multiple correlation coefficient in factor analysis or using the percentage of the Chi-square coefficient in correspondence analysis.

DEFINITION 8: The meaning of an institutional object $O_{I}$ is the system of institutional practices linked to the field of problems from which $O_{I}$ emerges at a given time.

We shall denote the meaning of $\mathrm{O}_{\mathrm{I}}$ by $\mathrm{S}\left(\mathrm{O}_{\mathrm{I}}\right)$. This notion of meaning is a construct that depends on the institution and on time. Symbolically, $\mathrm{S}\left(\mathrm{O}_{\mathrm{I}}\right)=\mathrm{P}_{\mathrm{I}}(\mathrm{C})$. If $\mathrm{I}=\mathrm{M}$, we talk about the mathematical meaning of an object.

The proposed notion of meaning allows us to introduce, in the didactical research program, the study of the structure of the system of social practices from which mathematical objects emerge, as well as their temporal evolution and institutional dependence. Also, the semiotic analysis of the institutional objects involves considering the situations that produce those social practices.

DEFINITION 9: The meaning of a personal object $O_{p}$ is the system of personal practices that a person $p$ carries out to solve the field of problems from which the object $O_{p}$ emerges at any given time.

Thus, this meaning depends on the subject and on time. Symbolically, $\mathrm{S}\left(\mathrm{O}_{\mathrm{p}}\right)=$ $\mathrm{P}_{\mathrm{p}}(\mathrm{C})$ Some personal practices can be observed, but not the 'interiorized' actions.

\section{Meaning and Understanding}

From the same field of problems $\mathrm{C}$ in which an institution I produces an object $\mathrm{O}_{\mathrm{I}}$, with the meaning $\mathrm{S}\left(\mathrm{O}_{\mathrm{I}}\right)$, a person could produce an object $\mathrm{O}_{\mathrm{p}}$ with a personal meaning $\mathrm{S}\left(\mathrm{O}_{\mathrm{p}}\right)$. The intersection of these two systems of practices is what the institution considers correct manifestations, that is to say, what the person 'knows' or 'understands' about the 
object $\mathrm{O}_{\mathrm{I}}$, from the institution's point of view. The remaining personal practices would be considered 'errors' according to the institution.

Concerning the practices that the students performed in our research to solve the contingency table problem, P1 to P3 would be considered correct from the point of view of the competence intended in secondary education. The teacher would consider that a particular student understands the idea of association if he or she shows one of these practices. On the contrary, P4 to P6 would be considered mistaken and related to a conceptual misunderstanding of association.

This situation is described in the following definition:

DEFINITION 10: The meaning of an object $O_{I}$ for a subject $p$, from the point of view of the institution I, is the subsystem of personal practices linked to a field of problems that are considered in I as adequate and characteristic practices solving these problems.

In an ideal situation, and within a given institution, we would say that a subject 'understands' the meaning of the object $\mathrm{O}_{\mathrm{I}}$, or that he/she 'has grasped the meaning' of a concept, if he/she is able to recognize its properties and representations, to relate it to other mathematical objects and to use it in the prototype problem situations within the institution. The understanding reached by a subject, at a given moment, will not be complete or null, but it will cover partial aspects of the different elements of meaning.

The concept of understanding that we have derived from definition 10 is closely related to the notion of 'good understanding' described by Sierpinska (1994, chap. 4), to which this authoress also attributes a relative character with respect to cultural or institutional settings.

We also consider that the notions of acts and processes of understanding, in their mental or subjective dimension, could be derived from our notions of meaningful practice and personal meaning. Nevertheless, the compatibility and complementarity of our theory of mathematical object and meanings with the theory of understanding developed by Sierpinska should require further study and development.

\section{A BACKGROUND TO THE PROPOSED THEORY}

In this Section, we shall present a brief summary of the sources that we have taken into account to support our theory and we shall mention authors and theories which agree with our viewpoints. We are aware, however, that a more in-depth study of the common ground and differences between our proposal and these theories should be carried out in the future.

The notion of meaning that we propose is inspired by Wittgenstein's ideas about meaning and understanding (Wittgenstein 1953), interpreted according to authors such as Kutchera (1979), McGinn (1984) and McDonough (1989). The doctrine of 'meaning as use' implies that the key concept is that of 'context embeddedness'. The context is understood here not merely as the physical environment of a linguistic utterance; rather the reference is made to the institutional and cultural context. As McDonough (1989) points out, Wittgenstein's Copernican revolution in the theory of meaning, still undigested by the sciences and technologies of human cognition, describes the neural system as conceptually dependent on a new centre: the institutional and the cultural context. In Didactics of Mathematics this approach is being persistently supported by Chevallard (1992), who places the study of 'The Didactic' (le didactique) within the confines of cognitive anthropology. 
The notions of institution, practice and object are used by Chevallard (1989; 1992) to define his concept of 'rapport au savoir', although we believe that the meaning that he attributes to these notions does not completely coincide with the one we have proposed in this paper. According to our theorization, not all practices are pertinent to the emergence of objects (some practices are incorrect, inappropriate or irrelevant). Moreover, a practice should be considered to be linked to the corresponding field of problems. The introduction of the notion of meaning (personal and institutional or, to put it in another way, psychological and epistemological) as a system of components elements of meaning, meaningful prototype practices- focuses our attention on the systemic and complex nature of meaning.

We consider it useful to distinguish between the name of an object, the object (as a cultural and psychological entity) and the system of practices linked to the solving of problems from which this cultural unit emerges, that is to say, the meaning of the object. This formulation allows us to better conceptualize the inference processes that are needed to characterize subjects' knowledge about mathematical objects, from the empirical manifestations of this knowledge.

With our definition of an institutional object we postulate the cultural existence of different objects, according to the reference institution, in situations in which the absolutist conception of Mathematics only perceives one object. This formulation is a consequence of the pragmatic assumptions which we have taken as a basis and their utility for the anthropological analysis of cognitive and didactical phenomena. Rotman (1988) has reached a similar conclusion in his semiotic analysis of mathematical activity, when he asserts that the numbers studied by the Babylonians, Greeks, Romans and present-day mathematicians are different. Nevertheless, we believe that these numbers are similar, because of the phenomenon of regressive appropriation.

We would refer the reader to our paper (Godino and Batanero 1994) in which we further develop the links between our idea of meaning and the ideas of authors such as Ausubel, Bunge, Douady, Putnam, Rotman, Steinbring, and particularly Vergnaud.

\section{A RESEARCH AGENDA FOR MATHEMATICS EDUCATION:}

\section{'SEMIOMETRY' AND THE ECOLOGY OF MEANING}

Below, we attempt to show the utility of the theorization we have presented in the setting of certain basic research questions in Mathematics Education. We shall also present some research examples that have been carried out from this theoretical perspective in the Department of Didactics of Mathematics at the Granada University in Spain.

We shall classify the research questions into two categories: The characterization of institutional and personal meanings - which we shall call the semiometry problem - and the study of the evolution and interdependence of meanings, in which the ecological paradigm could be a useful model (Godino 1993).

\section{Semiometry}

The consideration of the meaning of mathematical objects as systems of practices and the discrimination between personal and institutional meaning introduces, into the didactical 'problématique', the study of the structure and characterization of these theoretical entities. This characterization can be conceived as a 'measurement', not in a strict psychometric or mathematical sense, but in its general sense, that is, as the 
categorization of quantitative or qualitative variables, including the use of nominal, ordinal, interval or ratio measurement scales. Furthermore, it highlights the sampling nature of the process of selecting teaching and evaluation situations and of the students' manifestations and behavior. Thus, it contributes to overcoming the illusion of deterministic transparency that is frequently adopted when considering these problems.

A primary class of didactic research studies must be oriented towards the determination of institutional meanings, especially the meanings within mathematical institutions. We have to research into the characteristic uses of mathematical concepts, propositions and theories and to identify their different representations. This reference meaning may be compared with the meaning of mathematical objects in teaching institutions. We can also study the conditioning factors producing the development and changes of these meanings.

This type of research was carried out by Vallecillos (1994), who analyzed the institutional meaning of statistical hypothesis testing in University teaching. In her dissertation, Vallecillos showed that the original field of problems from which statistical inference has emerged refers to the search for inductive procedures of validation of empirical hypotheses. This problem has been substituted in the Neyman-Pearson theory by another related field of problems for which the test of hypothesis is a satisfactory solution: obtaining an inductive rule of behavior. Nevertheless, this shift in the problems that interest applied scientists and users of statistics is, in general, not sufficiently explained in the teaching of the subject.

The experimental study proved that the personal meanings of hypothesis testing built by students did not coincide, in general, with the statistical institutional meaning. This fact caused many errors, incorrect inference applications and misconceptions. In particular, subjects conceived erroneously the level of significance (or the p-value) in a statistical test as an 'a posteriori' probability of the hypothesis, given the data obtained. Thus, the students identified testing hypotheses with an inductive procedure to compute the probability of the hypotheses.

The theoretical system we have described in this paper also allows us to study, from a new perspective, the problem of assessing mathematical knowledge. By 'assessment' we mean, following Webb (1992) 'the comprehensive accounting of an individual's or group's functioning within mathematics or in the application of mathematics' (p. 662).

According to our theory, a subject's cognitive system (his/her conceptual and procedural knowledge, his/her intuitions, representation schemas, ...), that is to say, the network of personal objects at a given time, is an organized and complex totality. The distinction we have established between the domain of ideas or abstract objects (personal and institutional) and the domain of meanings, or systems of practices from which such unobservable objects emerge, is used to clarify the problem of looking for the correspondence between both domains, i.e., the problem of assessing institutional and personal knowledge.

The assessment of subjective knowledge necessarily requires performing inference processes, from the set of observed practices in evaluation situations, whose reliability and validity must be guaranteed (Messick 1991; Feldt and Brennant 1991). The complexity of this inference process is deduced, first of all, from the interrelationships between the knowledge of different mathematical objects. Subjects' knowledge concerning a given mathematical object cannot be reduced either to a dichotomy (to know or not to know) or to a degree or unidimensional percentage (to 
know x percent). Students' mathematical knowledge is not unidimensional; it is a complex system. Nor could it be measured on an interval or ratio scale. Assessment requires a multidimensional approach and weaker measurement scales (ordinal or nominal). Therefore, it is not appropriate to apply the classical psychometric theories of latent trait and domain mastery to the assessment of mathematical knowledge (Snow and Lohman 1991).

For example, in his dissertation, Estepa (1993) used students' strategies and judgments of association to assess their conceptions concerning statistical association. He used a written questionnaire made up by 10 descriptive association problems that include contingency tables, scatter plots and comparison of the same variable in different samples. The different signs and intensities of association and the agreement between subjects' previous theories and the empirical association in the data were also considered. Factor analysis of students' answers showed a multifactor structure in the judgment of association in which the influence of the aforementioned task variables was proven. Correspondence Analysis has demonstrated the multifactor structure of students' strategies (in which we included practices P1 to P6, described in the previous sections), which varied not only according to the mathematical contents of the problem, but also depending on the students' prior beliefs regarding the association suggested by the context of the problem.

The recognition of the complexity of meanings emphasizes the problem of assessing students' knowledge. Which criteria should be chosen for selecting the system of empirical indicators which characterize the cognitive state, i.e., a subject's knowledge concerning a mathematical object?

As a consequence of our theorization: The observable nature of social practices allows us to determine the field of problems associated with a mathematical object, as well as its institutional meaning, with the help of a phenomenological and epistemological study. The analysis of the task variables for this field of problems provides a first criterion to structure the population of possible tasks. From this population, a representative sample could be drawn to guarantee content validity for the assessment instrument. These two elements: field of problems and task variables thereof shall provide the first reference points in the selection of relevant evaluation situations for assessing subjective knowledge.

This 'semiometric category' of research studies may be related to the 'historicoempirical' approach to understanding in mathematics described by Sierpinska (1994).

\section{Ecology of meanings}

The problems involved in studying the evolution of institutional meanings of mathematical objects could be modeled with the help of the ecological metaphor (Chevallard 1989; Godino 1993): A particular object performs a function in different types of institutions and it is required to identify the necessary and/or sufficient conditions that allow this object to play its role in these institutions.

The notions of institutional object and meaning are intended to be used as conceptual instruments in this ecological and semiotical analysis of mathematical ideas.

The two types of studies described above would constitute the institutional and personal 'statics of meanings' in this ecological metaphor. Its aim would be to find the 'state and control variables' of meaning, considered as a system, at a particular moment in time. These studies of the static aspects of meaning should be supplemented with dynamic studies, which we are going to describe below. 
The study of changes that the institutional meaning of a mathematical object undergoes to become knowledge to be taught in different teaching institutions (curricular design, mathematical textbooks, ...) would constitute the dynamics of institutional meanings (didactical transposition (Chevallard, 1985), ecology of meanings).

We could quote, as an example of this type of research, the work by Ruiz Higueras (1993), concerning the study of students' conceptions about functions. She supported her research with a prior analysis of the evolution of the meaning of the function object throughout its historical development and of the institutional meanings presented to the students in her sample, using the analysis of official guidelines, textbooks and notes taken by students in the classroom.

Another fundamental problem in this category is the construction of adequate institutional meanings referring to a mathematical object for a specific school level, i.e., the curricular design. According to the theorization proposed, teaching should be based on the presentation of a representative sample of problems and other elements of the meaning of mathematical objects, taking into consideration the time and resources available.

This problem is tackled for combinatorial reasoning in Batanero et al. (1994) where a curriculum is presented for the teaching of Combinatorics, based on a sequence of didactical situations. The selection of the situations and their sequencing was supported by a prior study of the structure of simple combinatorial problems to provide a representative sample of this field of problems.

The meaningful learning (relational or significative) of the subject can be modeled as a sequence of 'acts of understanding', or acts of overcoming obstacles (Sierpinska 1990; 1994). The characterization of these acts and the identification of the mechanisms which produce the obstacles (Artigue 1990) is a central theme in the dynamics of personal meaning of mathematical objects. Metaphorically, the study of teaching and learning processes could be viewed as the study of the effects on personal meanings of 'shocks' of didactical sequences, which hold the elements of meanings.

Equally, a part of the characterization of the dynamics of personal meaning would be the study of the evolution of students' conceptions, i.e., the transformation of personal meanings as a consequence of instruction. Estepa (1993) employed systematic observation of classroom work by a pair of students and analysis of their interaction with computers. Using these data, he identified acts of understanding in relation to statistical association and assessed the overcoming of some obstacles by the students during the learning process.

\section{CONCLUSIONS}

All of us, both mathematics teachers and researchers, are interested in improving students' knowledge by means of instruction. This task requires the characterization of students' knowledge and calls for the clarification of the proper nature of knowledge. As Wheeler asks (1993), 'How can we assess what we do not know?' (p. 87). One could add, how can we teach what we do not know?

The search for appropriate answers to these theoretical problems has led us to elaborate the theory that we have presented, from which we could extract some general conclusions: 
1) We must postulate two dimensions of mathematical knowledge: institutional (epistemological) and personal (psychological), which are linked by complex interrelationships.

2) The meaning of mathematical objects (concepts, propositions, theories, . . . ) should be considered from a systemic complexity paradigm, on both the epistemological and the psychological level. We see the meaning of a mathematical object as an extensional entity that can play the role of a universe of reference from which to select assessment and teaching situations.

3) As students are subjects in different institutions, their knowledge is mediated by these institutions. Consequently, the characterization of institutional knowledge should be a prior step for assessing students' knowledge.

4) The phenomenological, semiotical and epistemological analysis of mathematical objects, as cultural entities, must provide criteria for the representative sampling of evaluation situations of the students' knowledge and for organizing didactical situations that favor their adequate evolution.

\section{Acknowledgement}

This research had been supported by the DGICYT grant PS93-0196, (M.E.C., Madrid).

\section{REFERENCES}

Artigue, M.: 1990, 'Epistémologie et Didactique', Recherches en Didactique des Mathématiques 10 (2/3), 241-286.

Balacheff, N.: 1990, 'Towards a "Problématique" for Research on Mathematics Teaching', Journal for Research in Mathematics Education 21 (4), 259-272.

Batanero, C., Godino, J.D. \& Navarro-Pelayo, V.: 1994, Razonamiento Combinatorio, Síntesis, Madrid.

Batanero, C., Estepa, A., Godino, J. D. \& Green, D.: 1996, 'Intuitive Strategies and Preconceptions about Association in Contingency Tables', Journal for Research in Mathematics Education 27 (2), 151-169.

Bishop, A.J.: 1988, Mathematical Enculturation: A Cultural Perspective On Mathematics Education, Reidel, Dordrecht.

Brousseau, G.: 1986, 'Fondements Et MŽthodes De La Didactiques Des MathŽmatiques', Recherches en Didactique des Mathématiques 7 (2), 33-115.

Brown, J.S., Collins, A. \& Duguid, P.: 1989, 'Situated Cognition And The Culture Of Learning', Educational Researcher, January-February, 32-42.

Bruner, J.: 1990, Actos De Significado. Mas Allá De La Revolución Cognitiva, Alianza Col. Psicología Minor, Madrid.

Cañón, C: 1993, La Matemática: Creación o Descubrimiento, Universidad Pontificia de Comillas, Madrid.

Chevallard, Y.: 1985, La Transposition Didactique - Du Savoir Savant au Savoir Enseigné, La Pensée Sauvage, Grenoble. 
Chevallard, Y.: 1989, 'Le Concept de Rapport au Savoir. Rapport Personnel, Rapport Institutionel, Rapport Officiel', Séminaire de Didactique des Mathématiques et de l'Informatique de Grenoble, IREM d'Aix de Marseille.

Chevallard, Y.: 1991, 'Dimension Instrumentale, Dimension Sémiotique de l'Activité Mathématique', Séminaire de Didactique des MathŽmatiques et de l'Informatique de Grenoble, IREM d'Aix de Marseille.

Chevallard, Y.: 1992, 'Concepts Fondamentaux de la Didactique: Perspectives Apportées par une Approche Anthropologique', Recherches en Didactique des Mathématiques 12 (1), 73-112.

D'Ambrosio, U.: 1994, 'Cultural Framing of Mathematics Teaching and Learning', in R. Biehler, R. W. Scholz, R. Sträßer, and B. Winkelmann (eds.), Didactics of Mathematics as a Scientific Discipline (pp. 443-455), Kluwer Academic Publishers, Dordrecht.

Dossey, J. A.: 1992, 'The Nature of Mathematics: its Role and its Influence', in D. A. Grouws (ed.), Handbook of Research on Mathematics Teaching and Learning, Macmillan, New York.

Estepa, A.: 1993, Concepciones Iniciales Sobre la Asociación Estadística y su Evolución como Consecuencia de una Enseñanza Basada en el uso de Ordenadores, (PhD Dissertation), Departamento de Didáctica de la Matemática, Universidad de Granada.

Feldt, L. S. and Brennan, R. L.: 1991, 'Reliability', in R. L. Linn (ed.), Educational Measurement (Third ed.), (pp. 263-331), American Council on Education and Macmillan, New York.

Freudenthal, H.: 1991, Revisiting mathematics education., Kluwer, Dordrecht.

Ernest, P.: 1991, The philosophy of mathematics education, Falmer Press, London.

Godino, J. D.: 1993, 'La metáfora Ecológica en el Estudio de la Noosfera Matemática'. Quadrante 2 (2), 69-79.

Godino, J. D. and Batanero, C.: (1994), 'Significado Institucional y Personal de los Objetos Matemáticos', Recherches en Didactique des Mathématiques 14 (3), 325-355.

Kitcher, P.: 1984, The Nature of Mathematical Knowledge, Oxford University Press, New York.

Kutschera , F. von: 1971, Filosofía del Lenguaje, Gredos, Madrid.

Lakatos, I.: 1976, 'A Renaissance of Empiricism in the Recent Philosophy of mathematics', in I. Lakatos, Philosophical Papers, Cambridge University Press, Cambridge.

McDonough, R.: 1989, 'Towards a Non-Mechanistic Theory of Meaning', Mind, xcviii (389), 1-21.

McGinn, C.: 1984, Wittgenstein on Meaning, Basil Blackwell, Oxford.

Messick, S.: 1991, 'Validity', in R. L. Linn (ed.), Educational Measurement (Third ed.), (pp. 13-104), American Council on Education and Macmillan, New York.

Morin, E.: 1977, El Método I; la Naturaleza de la Naturaleza. Cátedra, Madrid. 
Nunes, T.: 1992, 'Ethnomathematics and Everyday Cognition', in D.A. Grouws (ed.), Handbook of Research on Mathematics Teaching and Learning (pp. 557-574), Macmillan, New York.

Piaget, J.: 1979, 'Los Problemas Principales de la Epistemología de la Matemática', in J. Piaget (Director), Tratato de Lógica y Conocimiento Científico. 3: Epistemología de la Matemática, Paidós, Buenos Aires.

Rotman, B.: 1988, 'Toward a Semiotics of Mathematics', Semiotica 72 (1/2), 1-35.

Ruiz Higueras, L.: 1993, Concepciones de los Alumnos de Secundaria sobre la Noción de Función: Análisis Epistemológico y Didáctico. (PhD Dissertation), Departamento de Didáctica de la Matemática, Universidad de Granada.

Sierpinska, A.: 1990, 'Some Remarks on Understanding in Mathematics', For the Learning of Mathematics 10 (3), 24-36.

Sierpinska, A: 1994, Understanding in Mathematics, The Falmer Press, London.

Snow, R.E., and Lohman, D.R.: 1991, 'Implications of Cognitive Psychology for Educational Measurement', in R. L. Linn (ed.), Educational Measurement (Third ed.), (263-331), American Council on Education and Macmillan, New York.

Tymoczko, T.: (de.), 1986, New Direction in the Philosophy of Mathematics., Birkhauser, Boston.

Vallecillos, A.: 1994, Estudio Teórico-Experimental de Errores y Concepciones sobre el Contraste Estadístico de Hipótesis en Estudiantes Universitarios. (PhD Dissertation). Departamento de Didáctica de la Matemática, Universidad de Granada.

Vergnaud, G.: 1982, 'Cognitive and Developmental Psychology and Research in Mathematics Education: Some Theoretical and Methodological Issues', For the Learning of Mathematics 3 (2), 31-41.

Vergnaud, G.: 1990, 'La Théorie des Champs Conceptuels', Recherches en Didactiques des Mathématiques 10 (2/3), 133-170.

Vygotsky, L.S.: 1977, 'Pensamiento y Lenguaje', La Pléyade, Buenos Aires.

Webb, N. L.: 1992, 'Assessment of Students' Knowledge of Mathematics: a step Toward a Theory', in D.A. Grouws (ed.), Handbook of Research on Mathematics Teaching and Learning (pp. 661-686), Macmillan, New York.

Wheeler, D.: 1993, 'Epistemological Issues and Challenges to Assessment: What is Mathematical Knowledge?', in M. Niss (ed.), Investigations into Assessment in Mathematics Education, An ICMI Study, Kluwer, Dordrecht.

Wilder, R.: 1981, Mathematics as a Cultural System, Pergamon Press, Oxford.

Wittgenstein, L.: 1953, Investigaciones Filosóficas, Crítica, Barcelona. 